\title{
Predicting School Bullying Victimization: Focusing on Individual and School Environmental/Security Factors
}

\author{
Seokjin Jeong, ${ }^{1}$ Dae-Hoon Kwak, ${ }^{2}$ Byongook Moon, ${ }^{3}$ and Claudia San Miguel ${ }^{4}$ \\ ${ }^{1}$ Department of Criminology and Criminal Justice, University of Texas at Arlington, P.O. Box 19595, Arlington, TX 76019, USA \\ ${ }^{2}$ Illinois State University, USA \\ ${ }^{3}$ University of Texas at San Antonio, USA \\ ${ }^{4}$ Texas A\&M International University, USA
}

Correspondence should be addressed to Seokjin Jeong; sjjeong@uta.edu

Received 1 March 2013; Revised 29 April 2013; Accepted 18 June 2013

Academic Editor: John McCluskey

Copyright (C) 2013 Seokjin Jeong et al. This is an open access article distributed under the Creative Commons Attribution License, which permits unrestricted use, distribution, and reproduction in any medium, provided the original work is properly cited.

\begin{abstract}
Bullying behavior continues to be a salient social and health-related issue of importance to educators, criminal justice practitioners, and academicians across the country. While discourse on school bullying is abundant, previous studies are limited in explaining the predictive effect of factors such as individual/demographic variables, school environmental variables, and school antibullying preventive measures. Using a nationally representative sample of 12,987 private and public school students in the United States, the current study examines school safety measures and students' perceptions about school environments (or climate), especially school rules and punishment. Findings reveal that the variables of security guards, fairness and awareness of school rules, gangs and guns at school, students misbehaving, and teachers' punishment of students were statistically significant predictors of bullying victimization. Implications of these findings for school anti-bullying programs as well as directions for future research are discussed.
\end{abstract}

\section{Introduction}

In recent decades, school bullying and victimization, which continues to be a serious social and health problem in the United States, has received extraordinary levels of attention from the public, criminal justice practitioners, academicians, and educators [1-3]. A significant number of empirical studies indicate that bullying and victimization is an increasing problem on school grounds and one that has negative consequences for both bullies and their victims [3-8]. For example, the School Crime Supplement survey (2007) showed that 32 percent of students reported being bullied at school, while only 28 percent of students in 2005 reported being bullied [9]. Recently, Dinkes et al. [10] found that 75 percent of US public school principals indicated that schools reported one or more violent incidents to the police, and 25 percent of public schools reported school bullying on a daily/weekly basis. Numerous studies [11-15] also document that school bullying is physically and psychologically detrimental to the victims.
Limited empirical studies [16-22] have examined predictors of bullying victimization, and few have focused on individual and school-related factors. Yet these studies found that individual demographic factors (e.g., age, gender, and race) and school characteristics (e.g., presence of gangs at school, and police/school staff members' supervision) are significantly related to victimization. For example, a study by DeVoe et al. [17] found that victims of school bullying are more likely to be younger and white and to report the presence of gangs in their schools.

Most previous research on bullying, however, suffers from several limitations. First, the majority of prior research has focused on bullies, types of bullying, and related prevention/intervention strategies. Second, many studies have focused on physically aggressive bullying and victimization while ignoring psychologically/emotionally aggressive victimization, despite the fact that many children are known to be bullied not only physically, but also psychologically/emotionally $[3,23]$. Third, while schools have attempted to create safer environments by implementing a variety of 
preventive strategies and programs, such as the use of school security technologies (e.g., metal detectors, and surveillance cameras), school security guards, and anti-school-bullying programs during the last decade, few studies have examined whether these preventive strategies and technologies have any significant effect on reducing bullying victimization $[17,22]$.

The current study, using a nationally representative sample of adolescents in the United States, takes a more holistic approach and addresses these limitations. Primarily, the focus of the current study is to determine whether various school safety strategies, the school environment, and individual social demographic factors are significantly related to each of the school bullying victimization categories. It is hypothesized that students who attend schools where there is a heightened safety outlook (including school safety strategies for a more safe and protective school environment/climate) will have less incidents of victimization than schools that do not have such an environment. Additionally, this study will examine three different categories of school bullying victimization (physical, psychological, and both physical and psychological bullying victimization) in an effort to help schools develop more strategic plans for reducing bullying and victimization.

\subsection{School Bullying Victimization and Negative Consequences.} According to Olweus [13], school bullying is defined as physical and/or emotional harm inflicted by students within the geographical boundaries of a school campus. More often, bullying includes repeated incidents of harm, is generally characterized by an imbalance of power and/or an asymmetrical relationship among students [7, 13], and harm is directed at specific students (or targets) [24]. Victimization (being bullied) of school bullying is therefore defined as repeated exposure to physical and emotional harm from more powerful students on campus [13].

Although the prevalence of victimization of school bullying varies in empirical studies, prior research has found that a significant number of children have been victims of school bullying [13, 25-27]. For example, a study by Silvernail et al. [26], using a sample of 4,496 youths in public schools, found that 41 percent of students reported being teased in a mean way and 38 percent reported being victims of physical bullying (i.e., being hit, kicked, and/or pushed). Orpinas et al. [25] found that almost half of the students in the sample were victims of physical bullying and similar numbers were emotionally and/or verbally bullied at school. More recently, the 2007 Youth Risk Behavior Survey indicated that approximately 8 percent of adolescents (aged 12-18 years) in the sample were being threatened and injured by other students. Overall, the results consistently report that our children are victimized by other students on school ground.

A number of empirical studies have found that school bullying has detrimental effects on a victim's physical and psychological well-being and also hurts his/her academic standing [7, 28-35]. For example, victims of school bullying are more likely to suffer serious mental health disorders, such as depression, anxiety, loneliness, and unhappiness, and are at greater risk for committing suicide [28, 33-35].
In addition, bullied victims are more likely to experience relational problems with their school peers, to be rejected by their peers, to dislike school, and to have lower grades $[7,29,33]$. These findings clearly show that victimization of school bullying is serious problem that requires changes to school environments in order to improve safety among students.

1.2. Predictors of School Bullying Victimization. Although any student can be a victim of school bullying, there are consistent characteristics of victims. Several empirical studies have found that individual demographic characteristics (e.g., gender, age, and race) are significantly related to school bullying victimization [16-18, 20, 21]. For example, Graham and colleagues [18] and Rodkin and Berger [36] found that girls are more likely than boys to be victimized at school and to identify themselves as victims. Age and grade level have also been found to be significant predictors of being victimized [13, 16, 17]. A study by Whitney and Smith [21] shows that risk of being bullied decreases with age. DeVoe et al. [17] also found that 14 percent of 6th graders in the sample reported being victimized, while only 2 percent of 12 th graders were victims of school bullying. Similarly, Olweus [13] found that elementary and middle school students were more vulnerable to victimization than high school students. Regarding the relationship between race and school bullying victimization, the findings are mixed. A study by Seals and Young [37] indicates no significant difference between whites and racial minorities, while Mouttapa et al. [38] found that Asian youths were more likely than other racial groups being victimized at school. Other studies [39-41] found that students with mental health problems (e.g., anxiety, depression, unhappiness, aggression, and emotional difficulties) appear to be more vulnerable to school bullying victimization than students without mental health problems.

Prior empirical studies also indicate that negative interactions with parents and a home environment where domestic violence is present are significantly related to school victimization. Youths who have been rejected by parents and/or exposed to a harsh home environment, such as hostility and violence among family members, are more likely to be victims of school bullying [42-45]. In addition to individualrelated characteristics, lifestyle and opportunity influence bullying victimization. Adolescents who are more exposed to opportunities to engage in risky behavior (e.g., skipping class or getting involved in a fight) have a higher probability for victimization than others.

Other studies [46-49] found that school characteristics and climate (i.e., school conduct/discipline, teachers' attitudes, teachers' support, rule clarity/enforcement, and students' respect) are significant predictors of school victimization. In contrast, adolescents attending schools where teachers paid attention to bullying and intervened in or stopped bullying problems were less likely to be victimized [48].

Also, research shows a significant relationship between school safety/adult supervision and bullying victimization at school [49-51]. These studies found that students were 
less likely to be victimized when schools increased staff supervision of student activities in hallways and in the cafeteria. Additionally, students attending schools in which teachers were aware of school policies on bullying and in which school professionals handled victimization problems adequately tended to be victimized less often [50]. In contrast, lower levels of involvement by teachers in the establishment and enforcement of policies on aggressive student behavior were associated with higher rates of bullying and victimization [52].

Gottfredson and his colleagues [53] reported on a multilevel study of the effects of the school climate on students' victimization using a large national sample of secondary schools from the National Study of Delinquency Prevention in Schools. The researchers predicted that better discipline management (i.e., perceptions of the fairness of school rules/rule enforcement and perceptions of the clarity of rules) is related to lower levels of student victimization. Results from another study on the effects of school level security and related issues on the degree of school bullying victimization have been mixed. Schreck et al. [8] found no evidence that school guardianship, such as school guards/hallway supervision, metal detectors, and visitor sign-in protocols, affected overall rates of students' victimization in school once individual and school characteristics were controlled. However, they found that students at schools with locker checks and corporal punishment policies experienced less victimization.

1.3. Theory of School Climate and School Bullying Victimization. A few studies have focused on the role that the school climate, including school characteristics, plays in bullying victimization; most studies, however, overlook the ecological dimension of school bullying and victimization although framing school violence within this model is perhaps the most cogent approach. Bronfenbrenner [54], in discussing a more holistic perspective to human growth and development, proposed an ecological model governed by the reciprocal relationship an individual has with his/her environment. Extrapolating from his theory, a few researchers have proposed mechanisms of bullying victimization by employing an ecological model whereby adolescent development is influenced by both their proximal environment and other environmental contexts including fluid interactions with parents, peers, teachers, and the school climate $[55,56]$. Bullying victimization can thus be best understood within this framework.

The central features of ecological perspectives are four different ecological levels of interaction: (i) microsystem; (ii) mesosystem; (iii) exosystem; and (iv) macrosystem [54]. The microsystem involves interactions with the individual's immediate or proximal environment. The microsystem includes patterns of activities, roles, and interpersonal relationships. Families are generally the first microsystem within which adolescents function [54]. For instance, parents may have the closest and the greatest influence on an adolescents' behavior. The second ecological system is the mesosystem, which refers to interrelations of two or more elements within the microsystem. Harmonious relationships between parent and peers or parents and school may influence an adolescent's behavior. Thirdly, the exosystem is defined as a "system that is not in direct interaction with the developing person but has indirect effects on the person" [54, p. 26]. For instance, parents in poor neighborhoods may face greater obstacles in taking proper care of their children. If there is a lack of resources in such neighborhoods, the relationship between lack of parental support and lack of community resources may not directly affect an adolescent's behavior, but indirectly affect it. The last system is identified as the macrosystem, which includes influences by one's culture, norms, and laws of society [54], In sum, the theory of ecology of human development has not produced one uniform set of explanations for interaction between individuals and environment. Rather, it provides many possible explanations, such as various interactions between parent, peer, school, and/or community factors from all of these ecological sources. It does, however, provide the best theoretical framework for studies on bullying victimization because it describes fluid and reciprocal interactions between peers, some of which negatively impact those in asymmetrical power relationships on campus.

1.4. Research Questions and Hypotheses. In sum, we believe that further research is necessary to better understand the etiology of bullying victimization, especially focusing on the effects of school prevention/intervention strategies and school environments on victimization. We first examine whether school safety equipment and strategies are significantly related to various types of bullying victimization. Based on the extant literature, it is expected that security guards and security equipment have significant effects on various types of bullying victimization. Second, we expect that school environments (e.g., awareness/fairness of school rules and punishment and presence of gangs and guns at school) are significant predictors of each type of victimization. Third, we examine whether individual demographic characteristics and deviant behaviors are significantly related to bullying victimization.

\section{Method}

2.1. Sample and Procedure. Self-reported data on bullying victimization were collected from 22,686 adolescents in the 2005/2007 school crime supplement (SCS) as a part of the National Crime Victimization Survey in the United States. SCS uses a rotating panel design of randomly selected households and is a collaborative cross-national study examining school-related victimization among school-aged adolescents to provide specific information for policymakers and practitioners. In particular, SCS is designed to examine several direct and indirect characteristics of bullying victimization and bullying victims. In addition, the SCS component asks respondents about school life, participation in extracurricular activities, access to drugs, weapon carrying, and other school-related issues. To obtain a nationally representative sample, data were collected from school-aged adolescents (between 12 and 18 years old) who were in middle school 
and high school. Since the purpose of the current study is to understand school safety measures related to victimization at school, the analysis is restricted to those who were enrolled in private or public education programs during the six months prior to the interview. Therefore, a total of 12,987 students were eligible for the current study $(59.3 \%(N=6833)$ in 2005 and $55.1 \%(N=6154)$ in 2007 , resp. $)$.

2.2. Dependent Variable. Even though bullying is considered an aggressive behavior [57], bullying includes more subtle patterns of violence such as taunting, teasing, name calling, and spreading rumors [13]. In line with this assumption regarding more subtle forms of bullying, a review of prior research suggested key differences between students whose bullying victimization involved physical or emotional/verbal abuse versus students who did not experience any victimization. For the purpose of the present study, therefore, bullying victimization was defined by the most widely used criteria [13]: (0) no victimization; (1) physical victimization; (2) emotional victimization; and (3) both types of victimization. Physical victimization is defined by four items: "During this school year, has any student bullied you, such as threatened you; pushed/shoved/tripped; you done anything to you against your will; and destroyed your property." The definition of emotional victimization also comprises four items: "During this school year, has any student bullied you, such as made fun of you or called you names; spread rumors; excluded you" and "has anyone called you an insulting or bad name at school having to do with your race, religion, ethnicity, disability, gender, and sexual orientation." Responses for each victimization item were recorded into a categorical variable which was coded 0 if the respondent had not experienced any such victimization incidents at school, coded 1 if the respondent had experienced at least one of these physical victimization incidents at school, coded 2 if the respondent had experienced at least one of the emotional victimization incidents at school, and coded 3 if the respondent had experienced both physical and emotional victimization incidents at school. The dependent variable used in our analysis differs from that in some prior studies in that it adds both physical and emotional victimization as a separate category along with traditional categories including physical and emotional victimization. This particular process allows both physical and emotional victimization category to be compared to a reference category (i.e., none) simultaneously.

2.3. School Characteristics. The SCS records contained measures of several characteristics commonly expected to differentiate types of victimizations (see Table 1). Two groups of school security measures were supposedly related to school bullying victimization. The measured variable school security guards included whether a respondent's school had security guards or staff/adults in the hallways. We also employed the school safety equipment measure that asked whether a respondent's school had a metal detector, locked doors, or security cameras. Among these three items, locked doors and security cameras were selected as proxy variables for school safety equipment. The school safety measures had a dichotomous $(1=$ yes $/ 0=$ no $)$ response.
In addition to school safety measures, we employed school climate measures including fairness of school rules, awareness of school rules, and awareness of school punishment. Three items were combined to measure fairness of school rules: "School rules are fair"; "Same punishment for breaking rules"; and "School rules strictly enforced" (see Table 1). It is expected that students who believe that school rules are fairly and strictly administrated will be less likely to have bullying victimization than other students who distrust school's discipline management [53]. For further analysis, the average scores were calculated based on these three items so that the higher scores indicate that students think school rules/punishments are trustworthy and fair. The reliability coefficient (Cronbach's $\alpha$ ) for fairness of school rules was 0.67 . The variable awareness of school rules asked whether "everyone knows school rules," and awareness of punishments asked whether "students know the punishment." Each item had a four-point Likert-scale response ranging from 1 (strongly disagree) to 4 (strongly agree).

Previous research on bullying victimization found that school-related variables, such as students misbehaving, gangs at school, guns at school, types of school, and school location, were associated with bullying victimization [17]. In particular, it is hypothesized that such school environment including students misbehaving, gangs or guns at school are positively related to each type of victimization. To examine the effects of school-related characteristics on victimization, we used three variables: students misbehaving, gangs at school, and guns at school. A single item is used to measure fellow students' misbehavior at school: "How often are you distracted from doing your schoolwork by students misbehaving." The response options for the item ranged from $1=$ never, $2=$ Almost never, $3=$ sometimes, and $4=$ most of the time. Gangs at school ("Are there any gangs at your school?") and guns at school ("Do you know any students who have brought a gun to your school during this school year?") were coded into a binary variable $(1=$ yes $/ 0=$ no). In addition, since public schools and schools located in urban areas may have a higher percentage of bullying victimization compared with their counterparts (i.e., private schools and rural areas) [21], types of school $(1=$ private and $0=$ public $)$ and school location $(1=$ urban and $0=$ rural $)$ were also included in the model in order to control the potential intervening effects of type of school and school location on bullying victimization.

2.4. Individual Characteristics. Because prior research indicates that some social-demographic individual characteristics are significant predictors of bullying victimization, we examine whether age, gender, household income, race/ethnicity, deviant behaviors, academic performance, and extracurricular activities are significantly related to bullying victimization. Age is an interval level variable, ranging from 12 to 18 years old. Sex is a dichotomous variable, coding male as 1 and female as 0 . Race is also a dichotomous variable with nonwhite as 1 and white as 0 . Ethnicity is a dummy variable, coding Hispanic as 1 and non-Hispanic as 0 .

Additional measures of individual characteristics were skipping class and fighting in the last 6 months; all were 


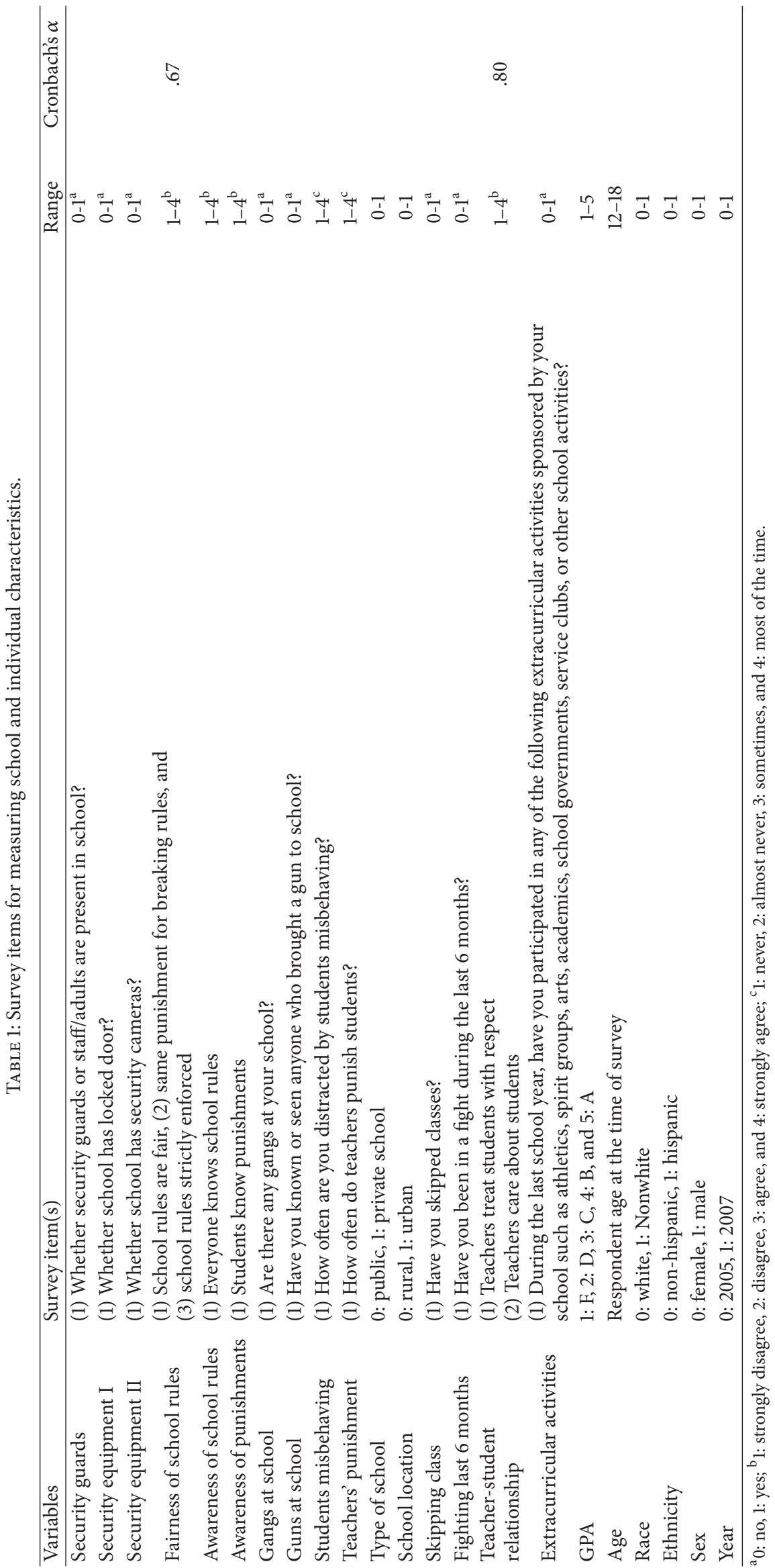


dichotomous variables coded 1 for yes and 0 for no. A single item, "During this school year, across all subjects have you gotten mostly?", was used to measure students' school performance, and the response options were $1=\mathrm{F} ; 2=\mathrm{D}$; $3=\mathrm{C} ; 4=\mathrm{B}$; and $5=\mathrm{A}$. The SCS also measured students' participation in extracurricular activities consisting of items asking, "Have you participated in athletic teams, spirit groups (e.g., cheerleading or pep club), performing arts, academic clubs, or student government?," which we coded as ExtraCurricular Activities $(1=$ yes $/ 0=$ no). (In order to check for any possible multicollinearity (MC) problems among independent and control variables, the variance inflation factor (VIF) and tolerance statistics were calculated. Results confirmed that there was no severe MC problem among those variables (VIF $<1.46$, tolerance $>0.69$ ). Thus, the current study simultaneously included all available school safety and socioeconomic variables as well as control variables in the regression models).

2.5. Analytic Strategy. Since the primary dependent variable was a nominal variable with four discrete categories (i.e., consisting of unordered categories of no bullying, physical bullying, verbal bullying, and both physical and verbal bullying victimization), a multinomial logistic model (MNLM) was used to estimate the effects of school safety variables on school bullying victimizations. The MNLM is preferable to binary logistic regression analysis because it takes account of the unordered nature of the dependent variable and provides more efficient estimations by producing multiple logits simultaneously [58].

Missing values (data) are important because the improper handling of missing values will produce biased coefficients [59]. Thus, a missing data analysis was also conducted to ensure the quality of the analysis. The preliminary results confirmed that the missing observations of most of the variables in this study's data occur completely at random. However, some independent variables were found to be significantly different between complete and incomplete data (e.g., school guard). To correct this problem, we estimated the multinomial logistic regressions using the sampling weight option (pweights) in STATA [60]. In particular, we employed an inverse probability weight (IPW) procedure so that all observations from the complete data were given more weight than others when computing estimates. An IPW procedure consists of two practical steps. First, a logistic regression analysis was conducted to estimate a subject's probability of being fully observed (Prob $\left[R=[1,1,1, \ldots, 1] \mid Y_{0}\right]$ ). Then, the inverse of these probabilities were calculated and used to re-weight contributions to generalized estimating equations in a completer-only analysis (i.e., MNLM with pweights). Finally, STATA yields robust standard errors that automatically adjust potential misspecifications bias since probabilities are only estimated in the main model [61].

\section{Findings}

Table 2 illustrates the descriptive statistics for the dependent and independent variables used in this analysis. Of 12,987 students, approximately 33 percent of students reported experiencing some form of bullying in the previous school year. Among those bullied students, slightly more than half had been emotionally bullied (52 percent), and about 39 percent had experienced both physical and emotional bullying, followed by physical bullying (nine percent). This relatively low level of bullying victimization was found to be in several large-scale studies [1]. One recent study found that almost a third (29.9 percent) of their sample (15,000 US junior high and high school students) reported moderate to frequent involvement in bullying including the bully, the victim, or the bully-victim [7].

In terms of school safety measures, most schools had security guards (and/or assigned police officers), school staff members, or other adults supervising the hallways and classrooms (70 percent). Most schools had security equipment, such as locked entrance or exit doors (61 percent) or security cameras (70 percent), to monitor and secure the school during the day.

Most students also reported that school rules were fair and that they were aware of school rules and punishments. Some students reported gangs at school and that they knew of students who had brought a gun to their school (27 percent and five percent, resp.). With regard to demographic characteristics of students, few students had skipped a class (seven percent) or gotten into a fight (six percent) in the previous six months. Most of the students indicated that they had been participating in extracurricular activities such as athletics, spirit groups, and arts during the previous school year (67 percent). Finally, the average age of the students was about 15 years old, with a standard deviation of 1.90 , and about half of the students were male (51 percent). Roughly 20 percent identified themselves as nonwhite and Hispanic or Latino.

Table 3 presents results from a multinomial logistic regression with inverse probability weighted estimation. (We also estimated multinomial logistic regressions without IPW estimation. Although the magnitudes of coefficients were slightly changed, the significant results were remaining consistent throughout the models. Finally, it should be noted that the number of observations after listwise deletion of incomplete cases for both regression models are 6,988 and 6,891 , resp.). The results indicated that the variables of security guards, fairness and awareness of school rules, gangs and guns at school, students misbehaving, and teachers' punishment were found to be statistically significant predictors of overall bullying victimization. More specifically, students attending schools where security guards (and/or police officers) were present in the hallways were less likely to report being victims of physical bullying, emotional bullying, and both physical and emotional bullying $(\exp (b)=0.68$, 0.80 , and 0.74 , resp.). None of security equipment had a significant effect on each type of bullying victimization except one model. That is, students who attend schools with locked doors were more likely to report physical bullying victimization (exp $(b)=1.49$ ). If the level of fairness of school rules were to increase by one unit, the relative risk of experiencing emotional or both physical and emotional bullying (versus none) would be expected to decrease by 
TABLE 2: Descriptive statistics $(N=12,987)$.

\begin{tabular}{|c|c|c|c|c|c|c|c|c|}
\hline \multirow{2}{*}{ Variables } & \multirow{2}{*}{$N$} & \multirow{2}{*}{$\%$} & \multirow{2}{*}{ Mean } & \multirow{2}{*}{ SD } & \multirow{2}{*}{ Min } & \multirow{2}{*}{ Max } & \multicolumn{2}{|c|}{ Missing } \\
\hline & & & & & & & $N$ & $\%$ \\
\hline Bullying victimization & 11,950 & 92.02 & & & & & 1,037 & 7.98 \\
\hline 0: none & 8,044 & 67.31 & & & & & & \\
\hline 1: physical bullying & 339 & 2.84 & & & & & & \\
\hline 2: emotional bullying & 2,053 & 17.18 & & & & & & \\
\hline 3: physical and emotional bullying & 1,514 & 12.67 & & & & & & \\
\hline \multicolumn{9}{|l|}{ School characteristics } \\
\hline Security guards (1: yes) & 8,471 & 70.42 & & & & & 957 & 7.37 \\
\hline Locked doors (1: yes) & 6,924 & 61.15 & & & & & 1,664 & 12.81 \\
\hline Security cameras (1: yes) & 7,366 & 70.20 & & & & & 2,494 & 19.20 \\
\hline Fairness of school rules & & & 9.21 & 1.50 & 3.00 & 12.00 & 1,055 & 8.12 \\
\hline Awareness of school rules & & & 3.20 & .59 & 1.00 & 4.00 & 963 & 7.42 \\
\hline Awareness of punishments & & & 3.05 & .62 & 1.00 & 4.00 & 995 & 7.66 \\
\hline Gangs at school (1: yes) & 2,798 & 26.85 & & & & & 2,564 & 19.74 \\
\hline Guns at school (1: yes) & 643 & 5.41 & & & & & 1,100 & 8.47 \\
\hline Students misbehaving & & & 2.47 & .94 & 1.00 & 4.00 & 991 & 7.63 \\
\hline Teachers' punishment & & & 2.71 & .86 & 1.00 & 4.00 & 1,020 & 7.85 \\
\hline Type of school (1: private) & 989 & 8.18 & & & & & 889 & 6.85 \\
\hline School location (1: urban) & 9,808 & 75.52 & & & & & 0 & 0 \\
\hline \multicolumn{9}{|l|}{ Individual/demographic characteristics } \\
\hline Skipping classes (1: yes) & 826 & 6.92 & & & & & 1,052 & 8.10 \\
\hline Fighting last 6 months (1: yes) & 713 & 5.93 & & & & & 970 & 7.47 \\
\hline Teacher-student relationship & & & 6.41 & 1.06 & 2.00 & 8.00 & 988 & 7.61 \\
\hline Extracurricular activities (1: yes) & 8,066 & 66.88 & & & & & 927 & 7.14 \\
\hline GPA (5: As) & & & 4.10 & .84 & 1.00 & 5.00 & 1,153 & 8.88 \\
\hline Age & & & 14.83 & 1.90 & 12.00 & 18.00 & 0 & 0 \\
\hline Race (1: nonwhite) & 2,628 & 20.24 & & & & & 0 & 0 \\
\hline Ethnicity (1: hispanic) & 2,308 & 17.80 & & & & & 23 & .18 \\
\hline Sex (1: males) & 6,605 & 50.86 & & & & & 0 & 0 \\
\hline Year & & & & & & & 0 & 0 \\
\hline 0: 2005 & 6,833 & 52.61 & & & & & & \\
\hline 1: 2007 & 6,154 & 47.39 & & & & & & \\
\hline
\end{tabular}

Note: cumulative frequency may not be equal to the sample size $(n=12,987)$ due to missing values.

$\%$ : valid percent.

factors of 0.91 and 0.86 , respectively, given the other variables in the model are held constant. Similarly, students' perception of their awareness of school rules and punishments were also negatively related to physical bullying victimization and emotional bullying victimization, respectively. That is, students who reported a higher level of awareness of school rules were less likely to report victimization for physical bullying (exp $(b)=0.73)$. Similarly, students who knew punishments also were less likely to be emotionally bullied than their counterparts (exp $(b)=0.87)$.

In addition, the presence of gangs in respondents' schools increased the relative risk of bullying victimization, particularly for emotional or both physical and emotional forms. However, after controlling for students' individual characteristics, the presence of gangs in the schools became a nonsignificant predictor for physical bullying. The same patterns were found with respect to the presence of guns in the schools. In other words, students who knew of other students who had brought a gun to the school or saw another student with a gun at school were more likely to be victimized by emotional and both physical and emotional bullyings (exp $(\mathrm{b})=1.48$ and 1.88 , resp.). Students who were frequently distracted from doing their school work because other students were misbehaving (e.g., talking) were more likely to report victimization for all forms of bullying. Students who thought their teachers spent too much time punishing students had a greater risk of being victims of emotional and both physical and emotional bullyings (exp (b) $=1.13$ and 1.38). Finally, security equipment (i.e., security cameras), type of school (public versus private), and school location (urban versus rural) were not statistically significant predictors of bullying victimization.

With regard to individual and demographic characteristics, students who skipped classes were more likely to be 
TABLE 3: The results from multinomial logistic regression models with inverse probability weighted estimation.

\begin{tabular}{|c|c|c|c|c|c|c|c|c|c|c|c|c|}
\hline \multirow{2}{*}{ Variables } & \multicolumn{2}{|c|}{ Physical $^{1}$} & \multicolumn{2}{|c|}{ Emotional $^{1}$} & \multicolumn{2}{|c|}{$P \& E^{1}$} & \multicolumn{2}{|c|}{ Physical $^{1}$} & \multicolumn{2}{|c|}{ Emotional $^{1}$} & \multicolumn{2}{|c|}{$P \& E^{1}$} \\
\hline & $e^{\mathrm{b}}$ & SE & $e^{\mathrm{b}}$ & SE & $e^{\mathrm{b}}$ & SE & $e^{\mathrm{b}}$ & SE & $e^{\mathrm{b}}$ & SE & $e^{\mathrm{b}}$ & SE \\
\hline \multicolumn{13}{|l|}{ School characteristics } \\
\hline Security guards & $.68^{*}$ & .12 & $.80^{* *}$ & .06 & $.67^{* *}$ & .06 & .70 & .13 & $.80^{* *}$ & .06 & $.74^{* *}$ & .07 \\
\hline Locked doors & .81 & .13 & .88 & .06 & .88 & .07 & .82 & .13 & .88 & .06 & .86 & .07 \\
\hline Security cameras & 1.38 & .26 & .96 & .07 & 1.06 & .09 & $1.49^{*}$ & .29 & .94 & .07 & .99 & .09 \\
\hline Fairness of school rules & .89 & .06 & $.90^{* *}$ & .03 & $.83^{* *}$ & .03 & .91 & .07 & $.91^{* *}$ & .03 & $.86^{* *}$ & .03 \\
\hline Awareness of school rules & $.73^{*}$ & .11 & 1.12 & .07 & .89 & .07 & .75 & .12 & 1.10 & .08 & .89 & .07 \\
\hline Awareness of punishments & 1.04 & .15 & $.88^{*}$ & .06 & .92 & .07 & 1.04 & .16 & $.87^{*}$ & .06 & .89 & .07 \\
\hline Gangs at school & $1.50^{*}$ & .28 & $1.34^{* *}$ & .11 & $1.74^{* *}$ & .16 & 1.40 & .27 & $1.38^{* *}$ & .11 & $1.69^{* *}$ & .17 \\
\hline Guns at school & 1.30 & .39 & $1.56^{* *}$ & .22 & $2.11^{* *}$ & .30 & 1.10 & .35 & $1.48^{* *}$ & .21 & $1.88^{* *}$ & .28 \\
\hline Students misbehaving & $1.50^{* *}$ & .14 & $1.64^{* *}$ & .07 & $2.08^{* *}$ & .11 & $1.47^{* *}$ & .14 & $1.62^{* *}$ & .07 & $1.97^{* *}$ & .11 \\
\hline Teachers' punishment & 1.17 & .12 & $1.13^{* *}$ & .05 & $1.38^{* *}$ & .07 & 1.14 & .12 & $1.13^{* *}$ & .05 & $1.38^{* *}$ & .08 \\
\hline Type of school (1: private) & .64 & .23 & 1.11 & .13 & .95 & .15 & .69 & .25 & 1.08 & .13 & .95 & .16 \\
\hline School location (1: urban) & .95 & .17 & .93 & .07 & .91 & .08 & .96 & .18 & .97 & .08 & .99 & .10 \\
\hline \multicolumn{13}{|l|}{ Individual/demographic } \\
\hline Skipping classes & & & & & & & 1.55 & .41 & $1.47^{* *}$ & .20 & 1.23 & .19 \\
\hline Fighting last 6 months & & & & & & & $7.06^{* *}$ & 1.70 & $1.93^{* *}$ & .34 & $7.57^{* *}$ & 1.13 \\
\hline Teacher-student relationship & & & & & & & .99 & .08 & 1.02 & .04 & .99 & .05 \\
\hline Extra-curricular activities & & & & & & & $1.49^{*}$ & .28 & $1.29^{* *}$ & .11 & $1.25^{*}$ & .12 \\
\hline GPA & & & & & & & .89 & .08 & .92 & .04 & $.86^{* *}$ & .04 \\
\hline Age & & & & & & & 1.05 & .04 & .99 & .02 & .99 & .02 \\
\hline Race (1: Nonwhite) & & & & & & & .69 & .15 & .85 & .08 & $.68^{* *}$ & .08 \\
\hline Ethnicity (1: hispanic) & & & & & & & .86 & .18 & .86 & .09 & $.58^{* *}$ & .08 \\
\hline Sex (1: males) & & & & & & & $1.55^{*}$ & .26 & $.71^{* *}$ & .05 & 1.05 & .09 \\
\hline Year (1: 2007) & & & & & & & .82 & .13 & 1.07 & .07 & $1.29^{* *}$ & .11 \\
\hline Log Pseudo likelihood & \multicolumn{6}{|c|}{$-23,755.40$} & \multicolumn{6}{|c|}{$-22,627.13$} \\
\hline Wald chi-squared (df) & \multicolumn{6}{|c|}{$774.51(36)^{* *}$} & \multicolumn{6}{|c|}{$1,007.08(66)^{* *}$} \\
\hline Pseudo $R^{2}$ & \multicolumn{6}{|c|}{.08} & \multicolumn{6}{|c|}{.11} \\
\hline$N$ & \multicolumn{6}{|c|}{6,988} & \multicolumn{6}{|c|}{6,891} \\
\hline
\end{tabular}

${ }^{* *} P<.01,{ }^{*} P<.05$, SE: robust standard error, $e^{\mathrm{b}}$ : relative risk ratio, and $N$ : number of observations after listwise deletion of incomplete cases.

${ }^{1}$ None is the reference category.

emotionally bullied, and students who were in one or more physical fights at school in the previous six months were at greater risk of being victims of all forms of bullying (e.g., exp (b) for physical bullying $=7.06$ ). Students who participated in any type of extracurricular activities were more likely to report being victims of emotional and both physical and emotional bullyings. Students who maintained a higher GPA were less likely to be victims of both physical and emotional bullying (exp $(b)=0.86)$. Nonwhite and Hispanic students were less likely than whites and non-Hispanics to report being victims of both physical and emotional bullyings (exp (b) = 0.68 and 0.58 , resp.). Interestingly, while male students had a greater risk of being physically bullied than females, males were less likely than females to report emotional bullying. Finally, students who participated in the 2007 survey were more likely to have experienced both physical and emotional bullyings than those in the 2005 survey (exp (b) =1.29).

\section{Discussion}

Many researchers have examined the effects of individuallevel (or microlevel) characteristics on victimization of school bullying. And, only a few researchers have examined the effects of school safety equipment/strategies on victimization. However, existing research has usually tested for victimization based on non-nationally representative samples. Furthermore, the majority of prior victimization studies paid lesser attention to the etiology of different types of bullying 
victimization. The current study, using a national representative sample of youths in the United States, addresses several limitations of prior research on school bullying victimization. The study provides a test of variables that examine bullying victimization, especially focusing on individual/demographic and school environmental factors and school antibullying measures. Next, we summarize the key findings of the current study and implications for future research.

Overall, the current findings show that several individual characteristics (i.e., school performance, race, ethnicity, and gender) are significantly related to physical, emotional, or general (i.e., both emotional and physical) bullying victimization. Consistent with prior studies $[62,63]$, there is a negative association between academic achievement and victimization, in that academically competent respondents are less likely to report being victims of general school bullying. Also, the results show that boys are more likely to be bullied physically, while girls are more likely to report emotional bullying. These findings may suggest that boys are particularly susceptible to intimidation if they appear outwardly weak, while girls are more likely than boys to engage in relational bullying, to use rumors or misinformation, and to deny (or shun) targets [64]. Interestingly, the findings indicate that non-white adolescents are less likely than their white peers to report general school bullying, consistent with several prior findings that minority youth were less likely to be victimized than white youth $[7,30]$. However, there is some disagreement in the literature about racial differences in victimization. For example, Hanish and Guerra [65] found that white adolescents were the highest ethnic group at risk for victimization among different racial and ethnic groups. Findings from Seals and Young [37], on the contrary, found that there is no clear-cut evidence regarding the role of race and ethnicity on peer victimization. That being said, the relationship between race and ethnicity and vulnerability to bullying is still unclear and seems to vary. Because of the mixed findings regarding race and ethnicity, there is a need for further research to better understand the crucial role of race and ethnicity on peer victimization.

As expected, the findings indicate that students' delinquent behaviors are significantly related to school bullying victimization. The results show that those respondents who reported starting and/or being involved in physical fights at school in the previous six months have a greater risk of being a victim of physical and emotional bullying. Thus, it is highly possible that adolescents who behave aggressively toward others are indeed more likely to engage in interpersonal conflicts and then become a target of retaliation by peers, as suggested by Perry et al. [66]. In addition, this is consistent with previous findings that individuals engaged in risky or deviant behaviors, or whose lifestyle has exposed them to risky environments, are more likely to experience victimization [67-69].Unexpectedly, the results indicate that students who participate in various extracurricular activities are more likely to be subjects of emotional and general bullying. This finding contrasts with a prior study that found that extracurricular activities had a preventive effect on school violence [70]. Although further research is necessary to better understand the relationship between extracurricular activities and school bullying victimization, we can speculate that students who engage in extracurricular activities may have more opportunities to interact with bullies without staff supervision, especially if these activities are after school.

Various school environmental factors have significant effects on bullying victimization on school grounds. The presence, in school, of gangs and guns and teachers' frequent use of punishment have salient effects on both physical and emotional school bullyings victimization in the expected directions. We also found the prevalence of other students' distracting behaviors to be important in predicting both physical and emotional bullyings victimization. Conversely, students' perceptions of the fairness of school rules is negatively related to school bullying victimization, in that students who perceive greater fairness in school rules are less likely to be victimized physically and emotionally. These findings clearly indicate the importance of reducing students' exposure to adverse school environmental factors and improving school fairness in discipline and rules in order to reduce school bullying victimization.

Our analyses of school safety measures show that students attending schools where security guards (and/or police officers) are present in the hallways are less likely to be bullied. Students may feel safe in their school, and bullies may have limited opportunities to bully other students when schools employ security personnel [71]. Interestingly, the findings show that security equipment (i.e., locked doors) is not significantly related to school bullying victimization, even though the installation of security equipment in schools has become a popular preventive/deterrent measure. This finding is consistent with previous findings $[72,73]$ that schoolbased security equipment measures do not fundamentally address school bullying and victimization. It may be possible that locked doors create a heavily scrutinized, prisonlike feeling and that intrusive searches foster unwelcoming school environments [74]. Consequently, students may feel oppressed, which in turn may lead them to engage in school violence and bullying $[8,72,73,75]$. Regarding security cameras, the results from multinomial logistic regression analyses also yield unexpected results. Inconsistent with our expectation, security cameras (a proxy measure for security equipment) were found to be positively associated with physical bullying. That is, students at schools with security cameras tend to experience slightly more physical bullying victimization. It seems impossible to argue that the security cameras are a cause of physical bullying victimization. A feasible explanation for this particular finding is that schools installed security cameras because of increasing number of physical bullying victimization among students.

Notably, it is concluded that other school-related characteristics (i.e., gangs at school, guns at school, and teachers' punishment) are not effective in reducing physical victimization nor effective in reducing risk of emotional victimization. This result is perhaps not surprising. Students may not be involved in any type of inappropriate behaviors, if they are aware of the likelihood of being caught because of high security strategies and aware of the potential consequences because of school rules. This is true despite enrollment in schools characterized by poor security measures. 
Another explanation can be offered. According to $\mathrm{Ma}$ [76], a school climate characterized by students' disruptive behaviors may encourage bullies. Similarly, Nansel et al. [7] found that bullies reported a significantly poor perception of school climate. Bullies can incorporate and employ new techniques to bully other students. For example, bullies avoid physical interaction, which may result in physical signs (e.g., damaged property, physical signs or bruises, etc.), rather than verbally abuse or ignore the other students completely to avoid being caught by school officials (REVIEWER $1-$ no. 2 ).

\section{Future Directions and Implications}

Given our findings, an interesting question remains to be addressed: how can school safety strategies maximize effective outcomes that reduce the risk of being bullied? The answer to this question undoubtedly involves future research to test the efficacy of intervention strategies. First, research should closely examine the specific characteristics of school safety measures. As prior research has shown, perceptions of school safety conditions, such as gated/locked school entrances, visitor sign-in protocols, metal detectors, and security cameras have direct and indirect relationships with school violence [71]. By including these perceptions of the quality of school safety conditions, we can gain a better sense of the effect of safety strategies and their ability to prevent bullying victimization.

Second, school bullying interventions should also focus on the interplay between factors such as students' family, school, and community characteristics and students' proclivity to bully others at school. From the victim's perspective, it is important to understand how these factors interact with bullying and how these factors can be taken into account in order to develop better intervention programs that help to create safer school environments. Thus, it is becoming increasingly clear that a more holistic approach that moves beyond the geographical boundaries of a school may be needed to prevent school bullying. In addition, research should investigate the characteristics of bullying and of victimized children that are associated with students' experience of bullying victimization. Understanding these factors will lead to a more thorough evaluation of school violence and, subsequently, better prevention programs.

Overall, the results of the current study point to the critical role that school security guards/resource officers and the school climate/environment play in students' risk of becoming victims of school bullying. The results also show that individual background characteristics influence the risk of victimization. However, the main goal of the current study, namely, the effect of school security equipment on victimization, has not been realized. Nonetheless, our findings have obvious implications for preventing victimization in schools. First, the findings of the current study imply that gender is an important predictor of bullying victimization. Indeed, female students may be more vulnerable to emotional/verbal threats because of negative peer evaluation and loss of peer relationships, while males are more likely to be hurtful because of their attitude toward social dominance [77].
Therefore, interventions may work best when combined with gender-specific programs. In particular, school prevention strategies should focus on enhancing pleasant social experiences within the school, encouraging relational ties among female students. For male students, prevention efforts should focus more on fostering adaptive cognitions for aggressive and disruptive behavior.

As school bullying has received a significant amount of attention, several models and approaches of bullying prevention programs have emerged. According to Espelage and Swearer [50], there are over 300 school-based antibullying programs. Although all of the models vary by background, procedures, type of curriculum, and participants, each model shares common goals to achieve outcomes such as identifying the bully and victim, helping to cope with negative consequences of bullying, providing support and protection for victims, and reducing school bullying $[50,78,79]$. However, many evaluations studies have reported mixed and inconsistent results across samples and measures [80, 81]. The mixed results suggest that there is no single best approach to school bullying prevention. Based on our findings, many school-related characteristics were associated with emotional victimization across the United States. Although emotional bullying has detrimental effects on victims, relatively little attention has been given to this type of bullying [82]. In enhancing existing school bullying prevention program, both educators and stakeholders must be aware of less obvious acts of bullying victimization, such as emotional bullying.

The findings of the current study also imply that an unsupportive school climate clearly contributes to bullying victimization. The school-wide physical and social environments can serve as protective factors that contribute to a safe and healthy school. Thus, it is necessary to create a school climate that it proactive in inhibiting bullying and is transparent in its intolerance of bullying. In particular, it is important for schools to address students' distracting behaviors and the presence of gangs at school. According to Fox and Burstein [83], gangs and gang activity on school grounds increase violence because gangs are willing to terrorize an entire school, create fear among students, and disrupt the school climate. Strategies should focus on generating school resources that are likely to discourage students from joining gangs and engaging in violence, in order to decrease the level of violence in school. Overall, no matter how diligent and responsible security strategies are in preventing school bullying, there can be no absolute guarantees that bullying will not occur. However, if school staff/officials, parents, and the community seek interagency coordination and collaboration to better facilitate informal social control, these may prove to be decisive factors that can prevent school bullying and successfully suppress gang activities.

\section{References}

[1] J. F. Devoe, S. Kaffenberger, and K. Chandler, "Student reports from bullying: results from the 2001 School Crime Supplement to the National Crime Victimization Survey," National Education For Education Statistics, pp. 1-26, 2005. 
[2] D. C. Gottfredson, Schools and Delinquency, Cambridge University Press, New York, NY, USA, 2001.

[3] B. Moon, H.-W. Hwang, and J. D. McCluskey, "Causes of school bullying: empirical test of a general theory of crime, differential association theory, and general strain theory," Crime and Delinquency, vol. 57, no. 6, pp. 849-877, 2011.

[4] J. R. Blosnich and R. M. Bossarte, "Comparisons of intimate partner violence among partners in same-sex and opposite-sex relationships in the United States," American Journal of Public Health, vol. 99, no. 12, pp. 2182-2184, 2009.

[5] N. A. Card and E. V. E. Hodges, "Peer victimization among school children: correlations, causes, consequences, and considerations in assessment and intervention," School Psychology Quarterly, vol. 23, no. 4, pp. 451-461, 2008.

[6] J. F. Devoe, K. Peter, P. Kaufman et al., "Indicators of school crime and safety," National Center For Education Statistics, pp. 1-179, 2002.

[7] T. R. Nansel, M. Overpeck, R. S. Pilla, W. J. Ruan, B. SimonsMorton, and P. Scheidt, "Bullying behaviors among US youth: prevalence and association with psychosocial adjustment," Journal of the American Medical Association, vol. 285, no. 16, pp. 2094-2100, 2001.

[8] C. J. Schreck, J. M. Miller, and C. L. Gibson, "Trouble in the school yard: a study of the risk factors of victimization at school," Crime and Delinquency, vol. 49, no. 3, pp. 460-484, 2003.

[9] National Center for Education Statistics, "Indicators of School Crime and Safety: 2010 Indicator 11: bullying at school and cyber-bullying anywhere," 2010, http://nces.ed.gov/programs/ crimeindicators/crimeindicators2010/ind_11.asp.

[10] R. Dinkes, E. F. Cataldi, G. Kena, and K. Baum, Indicators of School Crime and Safety: 2006, U.S. Department of Education, Washington, DC, USA, 2009.

[11] S. Greenbaum, B. Turner, and R. D. Stephens, Set Straight on Bullies, Pepperdine University Press, Los Angeles, Calif, USA, 1988.

[12] J. Isaacs, E. Hodges, and C. Salmivalli, "Long-term consequences of victimization by peers: a follow-up from adolescence to young adulthood," European Journal of Developmental Science, vol. 2, pp. 387-397, 2008.

[13] D. Olweus, Bullying at School, Blackwell Publishers, Oxford, UK, 1993.

[14] K. Rigby and P. Slee, "Suicidal ideation among adolescent school children, involvement in bully-victim problems, and perceived social support," Suicide and Life-Threatening Behavior, vol. 29, no. 2, pp. 119-130, 1999.

[15] G. Salmon, A. James, E. L. Cassidy, and M. A. Javaloyes, "Bullying a review: presentations to an adolescent psychiatric service and within a school for emotionally and behaviourally disturbed children," Clinical Child Psychology and Psychiatry, vol. 5, no. 4, pp. 563-579, 2000.

[16] M. G. Borg, "The extent and nature of bullying among primary and secondary schoolchildren," Educational Research, vol. 41, no. 2, pp. 137-153, 1999.

[17] J. F. DeVoe, K. Peter, P. Kaufman et al., Indicators of School Crime and Safety: 2004, U.S. Department of Education, Washington, DC, USA, 2004.

[18] S. Graham, A. Bellmore, and J. Juvonen, "Peer victimization in middle school: when self- and peer views diverge," Journal of Applied School Psychology, vol. 19, pp. 117-138, 2003.
[19] D. Olweus, "Bully/victim problems among schoolchildren: basic facts and effects of a school based intervention program," in The Development and Treatment of Childhood Aggression, D. J. Pepler and K. H. Rubin, Eds., Erlbaum, Hillsdale, NJ, USA, 1991.

[20] M. S. Stockdale, S. Hangaduambo, D. Duys, K. Larson, and P. D. Sarvela, "Rural elementary students', parents', and teachers' perceptions of bullying," American Journal of Health Behavior, vol. 26, no. 4, pp. 266-277, 2002.

[21] I. Whitney and P. Smith, "A survey of the nature and extent of bullying in junior/middle and secondary schools," Educational Research, vol. 35, pp. 3-25, 1993.

[22] S. L. Wynne and H.-J. Joo, "Predictors of school victimization: individual, familial, and school factors," Crime and Delinquency, vol. 57, no. 3, pp. 458-488, 2011.

[23] K. Bosworth, D. L. Espelage, and T. R. Simon, "Factors associated with bullying behavior in middle school students," Journal of Early Adolescence, vol. 19, no. 3, pp. 341-362, 1999.

[24] J. R. Sprague and H. M. Walker, Safe and Healthy Schools: Practical Prevention Strategies, Guilford Press, New York, NY, USA, 2005.

[25] P. Orpinas, S. Kelder, R. Frankowski, N. Murray, Q. Zhang, and A. McAlister, "Outcome evaluation of a multi-component violence-prevention program for middle schools: the Students for Peace project," Health Education Research, vol. 15, no. 1, pp. 45-58, 2000.

[26] D. L. Silvernail, A. M. Thompson, Z. Yang, and H. J. Kopp, "A survey of bullying behavior among Maine third graders," 2000, https://www.ncjrs.gov/App/Publications/abstract.aspx? ID $=198355$.

[27] P. K. Smith, H. Cowie, R. F. Olafsson et al., "Definitions of bullying: a comparison of terms used, and age and gender differences, in a fourteen-country international comparison," Child Development, vol. 73, no. 4, pp. 1119-1133, 2002.

[28] M. J. Boulton and P. K. Smith, "Bully/victim problems in middle-school children: stability, self-perceived competence, peer perceptions and peer acceptance," British Journal of Educational Psychology, vol. 12, pp. 315-329, 1994.

[29] S. K. Egan and D. G. Perry, "Does low self-regard invite victimization?” Developmental Psychology, vol. 34, no. 2, pp. 299-309, 1998.

[30] S. Graham and J. Juvonen, "Ethnicity, peer harassment, and adjustment in middle school: an exploratory study," Journal of Early Adolescence, vol. 22, no. 2, pp. 173-199, 2002.

[31] D. S. J. Hawker and M. J. Boulton, “Twenty years' research on peer victimization and psychosocial maladjustment: a metaanalytic review of cross-sectional studies," Journal of Child Psychology and Psychiatry and Allied Disciplines, vol. 41, no. 4, pp. 441-455, 2000.

[32] D. L. Haynie, T. Nansel, P. Eitel et al., "Bullies, victims, and bully/victims: distinct groups of at-risk youth," Journal of Early Adolescence, vol. 21, no. 1, pp. 29-49, 2001.

[33] G. W. Ladd, B. J. Kochenderfer, and C. C. Coleman, "Classroom peer acceptance, friendship, and victimization: distinct relational systems that contribute uniquely to children's school adjustment," Child Development, vol. 68, no. 6, pp. 1181-1197, 1997.

[34] J. J. Paul and A. H. N. Cillessen, "Dynamics of peer victimization in early adolescence," Journal of Applied School Psychology, vol. 19, no. 2, pp. 25-43, 2003. 
[35] W. Troop-Gordon and G. W. Ladd, "Trajectories of peer victimization and perceptions of the self and schoolmates: precursors to internalizing and externalizing problems," Child Development, vol. 76, no. 5, pp. 1072-1091, 2005.

[36] P. C. Rodkin and C. Berger, "Who bullies whom? Social status asymmetries by victim gender," International Journal of Behavioral Development, vol. 32, no. 6, pp. 473-485, 2008.

[37] D. Seals and J. Young, "Bullying and victimization: prevalence and relationship to gender, grade level, ethnicity, self-esteem, and depression," Adolescence, vol. 38, no. 152, pp. 735-747, 2003.

[38] M. Mouttapa, T. Valente, P. Gallaher, L. A. Rohrbach, and J. B. Unger, "Social network predictors of bullying and victimization," Adolescence, vol. 39, no. 154, pp. 315-335, 2004.

[39] J. Cranham and A. Carroll, "Dynamics within the bully/victim paradigm: a qualitative analysis," Educational Psychology in Practice, vol. 19, no. 2, pp. 113-132, 2003.

[40] W. M. Craig, R. D. V. Peter, and R. Konarski, "Bullying and victimization among Canadian school children," Applied Research Branch Strategic Policy Human Resources Development Canada, vol. 1, pp. 1-32, 1998.

[41] J. C. Lumeng, P. Forrest, D. P. Appugliese, N. Kaciroti, R. F. Corwyn, and R. H. Bradley, "Weight status as a predictor of being bullied in third through sixth grades," Pediatrics, vol. 125, no. 6, pp. e1301-e1307, 2010.

[42] R. A. Finnegan, E. V. Hodges, and D. G. Perry, "Victimization by peers: associations with children's reports of mother-child interaction," Journal of Personality and Social Psychology, vol. 75, no. 4, pp. 1076-1086, 1998.

[43] S. N. Georgiou, "Bullying and victimization at school: the role of mothers," British Journal of Educational Psychology, vol. 78, no. 1, pp. 109-125, 2008.

[44] A. Mohr, "Family variables associated with peer victimization: does family violence enhance the probability of being victimized by peers?" Swiss Journal of Psychology, vol. 65, no. 2, pp. 107-116, 2006.

[45] D. Schwartz, K. A. Dodge, G. S. Pettit, and J. E. Bates, "Friendship as a moderating factor in the pathway between early harsh home environment and later victimization in the peer group. The Conduct Problems Prevention Research Group," Developmental Psychology, vol. 36, no. 5, pp. 646-662, 2000.

[46] M. K. Holt and D. L. Espelage, "A cluster analytic investigation of victimization among high school students: are profiles differentially associated with psychological symptoms and school belonging?" Journal of Applied School Psychology, vol. 19, no. 2, pp. 81-98, 2003.

[47] S. S. Leff, T. J. Power, T. E. Costigan, and P. H. Manz, "Assessing the climate of the playground and lunchroom: implications for bullying prevention programming," School Psychology Review, vol. 32, no. 3, pp. 418-430, 2003.

[48] A. A. Payne and D. C. Gottfredson, "Schools and bullying: factors related to bullying and school-based bullying interventions," in Bullying: Implications For the Classroom, C. Sanders and G. Phye, Eds., pp. 159-176, Academic Press, San Diego, Calif, USA, 2004.

[49] P. K. Smith and S. Shu, "What good schools can do about bullying: findings from a survey in English schools after a decade of research and action," Childhood, vol. 7, no. 2, pp. 193212, 2000.

[50] D. L. Espelage and S. M. Swearer, Bullying in American Schools: A Social-Ecological Perspective on Prevention and Intervention, Lawrence Erlbaum, Mahwah, NJ, USA, 2004.
[51] C. M. Wienke Totura, A. E. Green, M. S. Karver, and E. L. Gesten, "Multiple informants in the assessment of psychological, behavioral, and academic correlates of bullying and victimization in middle school," Journal of Adolescence, vol. 32, no. 2, pp. 193-211, 2009.

[52] W. M. Craig, D. Pepler, and R. Atlas, "Observations of bullying in the playground and in the classroom," School Psychology International, vol. 21, no. 1, pp. 22-36, 2000.

[53] G. D. Gottfredson, D. C. Gottfredson, A. A. Payne, and N. C. Gottfredson, "School climate predictors of school disorder: results from a national study of delinquency prevention in schools," Journal of Research in Crime and Delinquency, vol. 42, no. 4, pp. 412-444, 2005.

[54] U. Bronfenbrenner, The Ecology of Human Development: Experiments By Nature and Design, Harvard University Press, Cambridge, Mass, USA, 1979.

[55] S. M. Swearer and B. Doll, "Bullying in schools: an ecological framework," Journal of Emotional Abuse, vol. 2, no. 2-3, pp. 723, 2001.

[56] S. M. Swearer and D. L. Espelage, "Introduction: a socialecological framework of bullying among youth," in Bullying in American Schools: A Social-Ecological Perspective on Prevention and Intervention, D. L. Espleage and S. M. Swearer, Eds., pp. 112, Lawrence Erlbaum, Mahwah, NJ, USA, 2004.

[57] H. Andershed, M. Kerr, and H. Stattin, "Bullying in school and violence on the streets: are the same people involved?" Journal of Scandinavian Studies in Criminology and Crime Prevention, vol. 2, pp. 31-49, 2001.

[58] S. Long, Regression Models For Categorical and Limited Dependent Variables, Sage Publications, Thousand Oaks, Calif, USA, 1997.

[59] J. L. Schafer, "Multiple imputation: a primer," Statistical Methods in Medical Research, vol. 8, pp. 3-15, 1999.

[60] S. Long and J. Freese, Regression Models for Categorical Dependent Variables Using Stata, Stata Press Publication, College Station, Tex, USA, 2006.

[61] J. M. Wooldridge, "Inverse probability weighted estimation for general missing data problems," Journal of Econometrics, vol. 141, no. 2, pp. 1281-1301, 2007.

[62] J. Juvonen, A. Nishina, and S. Graham, "Peer harassment, psychological adjustment, and school functioning in early adolescence," Journal of Educational Psychology, vol. 92, no. 2, pp. 349-359, 2000.

[63] H. Mynard and S. Joseph, "Bully/victim problems and their association with Eysenck's personality dimensions in 8 to 13 year-olds," British Journal of Educational Psychology, vol. 67, no. 1, pp. 51-54, 1997.

[64] W. B. Roberts, Bullying from Both Sides: Strategic Interventions for Working With Bullies \& Victims, Corwin Press, Thousand Oaks, Calif, USA, 2006.

[65] L. D. Hanish and N. G. Guerra, "The roles of ethnicity and school context in predicting children's victimization by peers," American Journal of Community Psychology, vol. 28, no. 2, pp. 201-223, 2000.

[66] D. G. Perry, L. C. Perry, and E. Kennedy, "Conflict and the development of antisocial behavior," in Conflict in Child and Adolescent Development, C. U. Shantz and W. W. Hartup, Eds., pp. 301-329, Cambridge University Press, New York, NY, USA, 1992.

[67] M. C. Augustine, P. Wilcox, G. C. Ousey, and R. R. Clayton, "Opportunity theory and adolescent school-based victimization," Violence and Victims, vol. 17, no. 2, pp. 233-253, 2002. 
[68] M. J. Hindelang, M. R. Gottfredson, and J. Garofalo, Victims of Personal Crime: An Empirical Foundation for a Theory of Personal Victimization, Ballinger, Cambridge, Mass, USA, 1978.

[69] R. J. Sampson and J. L. Lauritsen, "Deviant lifestyles, proximity to crime, and the offender-victim link in personal violence," Journal of Research in Crime and Delinquency, vol. 27, no. 2, pp. 110-139, 1990.

[70] L. W. Rodney, P. Srivastava, and D. L. Johnson, "A series of culturally relevant models to prevent school-age youth violence: a 4-year family and community violence prevention study," in School Violence and Primary Prevention, T. W. Miller, Ed., pp. 407-429, Springer, New York, NY, USA, 2008.

[71] J. McDevitt and J. Panniello, "National assessment of the School Resource Officer Programs: Survey of Students in three large new SRO program," National Institute of Justice final report, 2005, http://www.ncjrs.gov/pdffiles1/nij/grants/209270.pdf.

[72] M. J. Mayer and P. E. Leone, "A structural analysis of school violence and disruption: implications for creating safer schools," Education and Treatment of Children, vol. 22, no. 3, pp. 333-356, 1999.

[73] C. J. Schreck and J. M. Miller, "Sources of fear of crime at school," Journal of School Violence, vol. 2, pp. 57-79, 2003.

[74] L. A. Addington, "Cops and cameras: public school security as a policy response to columbine," American Behavioral Scientist, vol. 52, no. 10, pp. 1426-1446, 2009.

[75] P. A. Noguera, "Preventing and producing violence: a critical analysis of responses to school violence," Harvard Educational Review, vol. 65, pp. 189-212, 1995.

[76] X. Ma, "Bullying and being bullied: to what extent are bullies also victims?" American Educational Research Journal, vol. 38, no. 2, pp. 351-370, 2001.

[77] A. J. Rose and K. D. Rudolph, "A review of sex differences in peer relationship processes: potential trade-offs for the emotional and behavioral development of girls and boys," Psychological Bulletin, vol. 132, no. 1, pp. 98-131, 2006.

[78] D. P. Farrington and M. M. Ttofi, "How to reduce school bullying," Victims and Offenders, vol. 4, no. 4, pp. 321-326, 2009.

[79] J. Urbanski and S. Permuth, The Truth about Bullying: What Educators and Parents Must Know and Do, Rowman \& Littlefield, Lanham, Md, USA, 2009.

[80] S. M. Swearer, D. L. Espelage, T. Vaillancourt, and S. Hymel, "What can be done about school bullying? linking research to educational practice," Educational Researcher, vol. 39, no. 1, pp. $38-47,2010$.

[81] R. C. Vreeman and A. E. Carroll, "A systematic review of schoolbased interventions to prevent bullying," Archives of Pediatrics and Adolescent Medicine, vol. 161, no. 1, pp. 78-88, 2007.

[82] E. L. Young, D. A. Nelson, A. B. Hottle, B. Warburton, and B. K. Young, "Relational aggression among students," Education Digest, vol. 76, no. 7, pp. 24-29, 2011.

[83] J. A. Fox and H. Burstein, Violence and Security on Campus, Praeger, Santa Barbara, Calif, USA, 2010. 

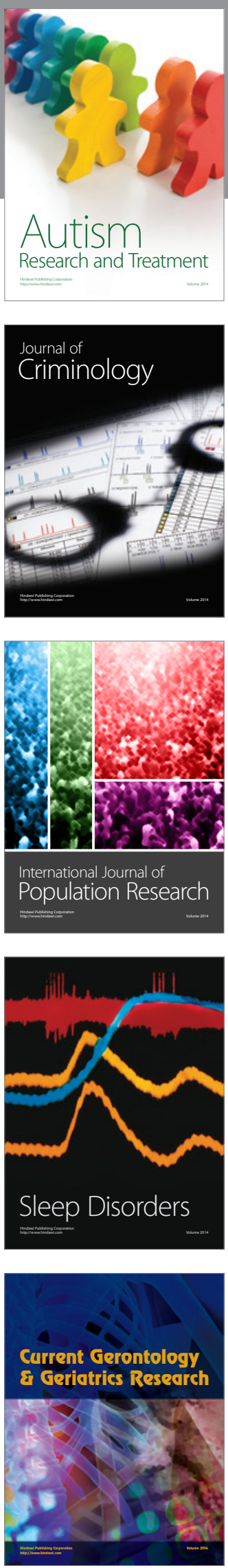
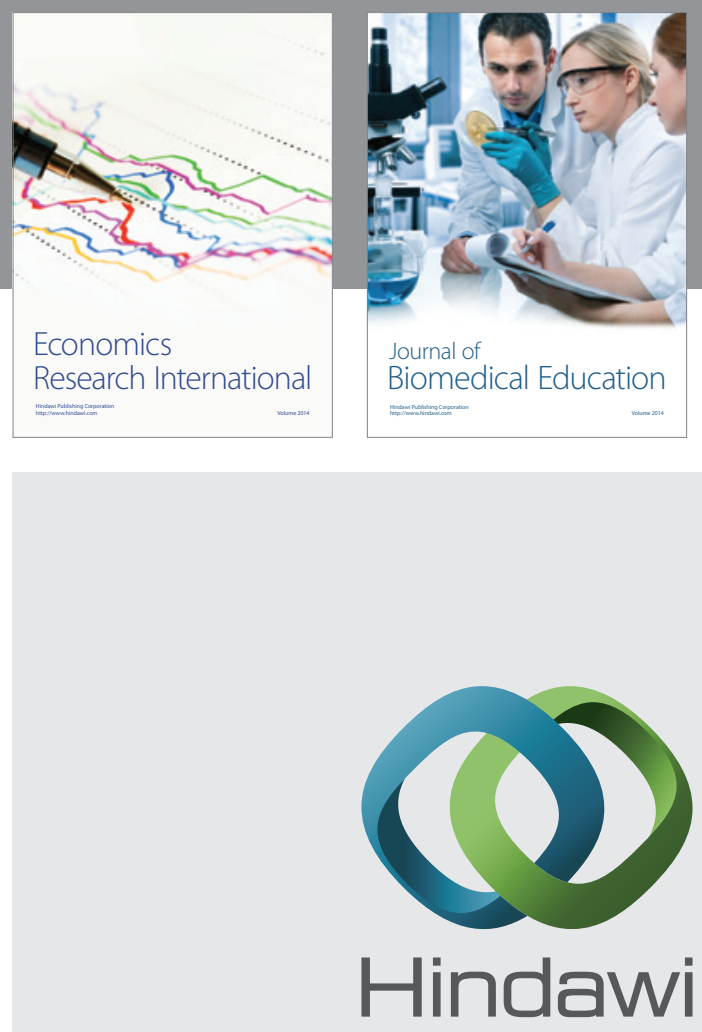

Submit your manuscripts at

http://www.hindawi.com
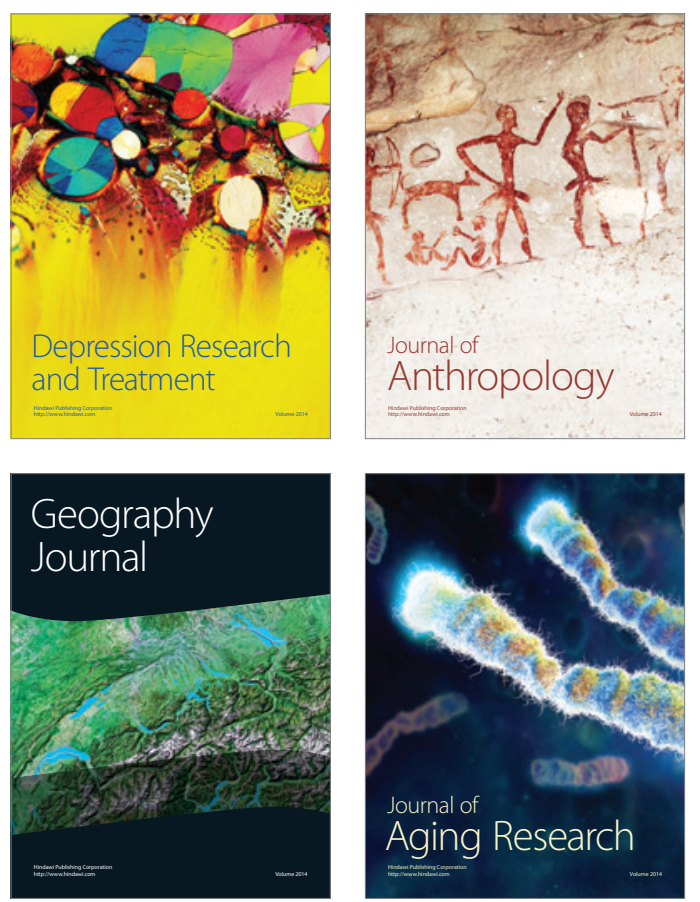
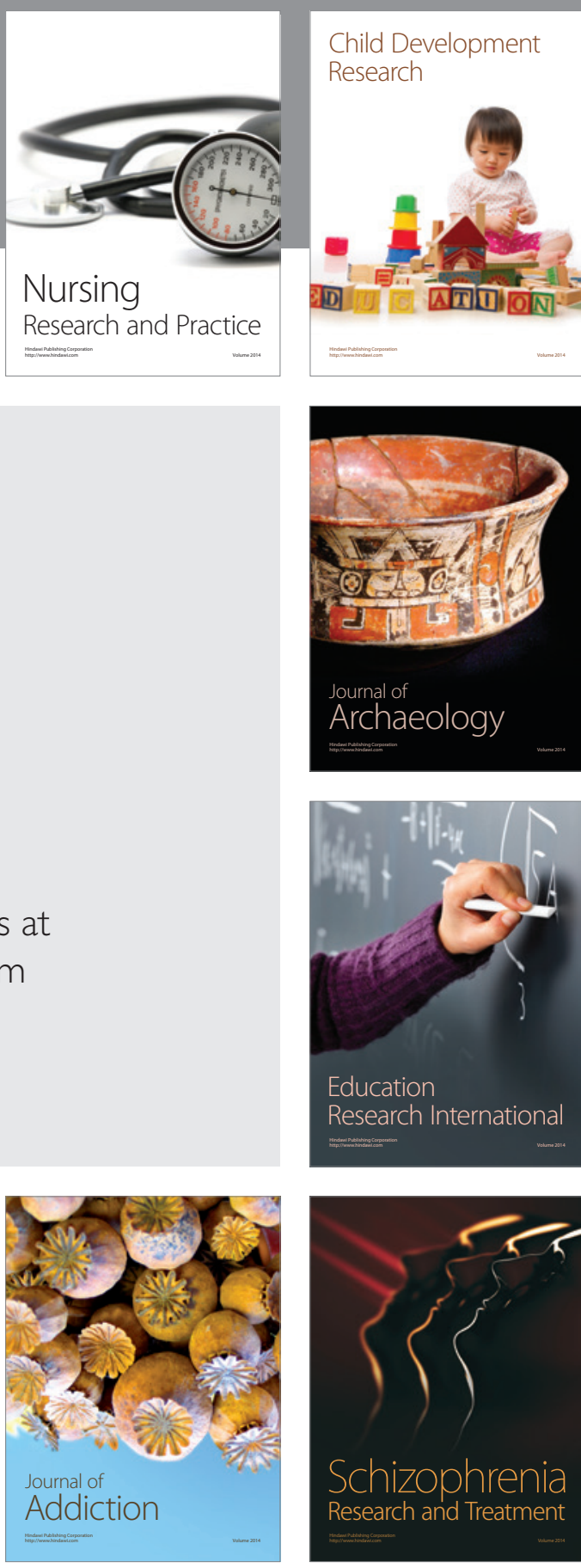

(D)
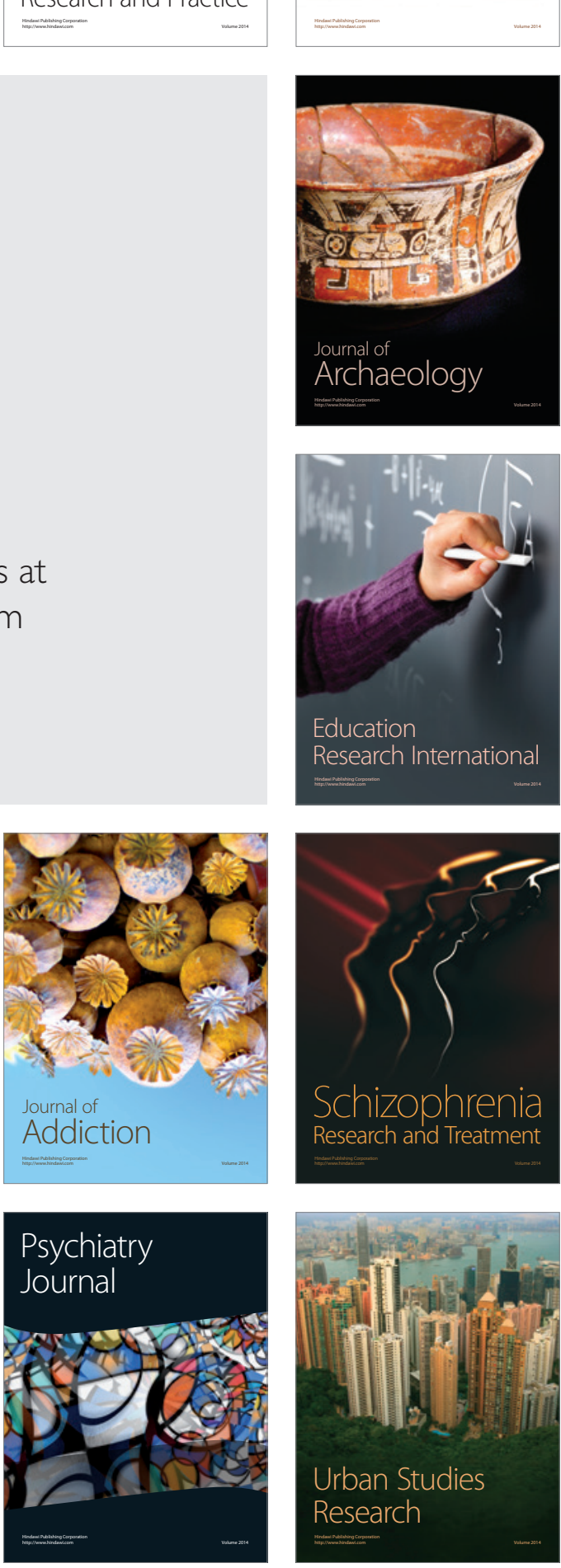